http://dx.doi.org/10.18542/rmi.v14i22.9649

\title{
AS ORGANIZAÇÕES NÃO GOVERNAMENTAIS E O PROGRAMA CISTERNAS EM BARREIRA (CE)
}

\section{NON-GOVERNMENTAL ORGANIZATIONS AND THE CISTERNAL PROGRAM IN BARREIRA (CE)}

Victória de Sousa XAVIER ${ }^{1}$

Universidade da Integração Internacional da Lusofonia Afro-brasileira

Andrea Yumi Sugishita KANIKADAN ${ }^{2}$

Universidade da Integração Internacional da Lusofonia Afro-brasileira

\begin{abstract}
Resumo: O presente trabalho propõe-se a estudar o Programa de Cisternas, implementado na região rural do município de Barreira (CE), uma vez que o acesso à água é um tema frequentemente discutido na comunidade. Na região, os problemas acerca do abastecimento de água são diversos, principalmente para as comunidades mais afastadas do centro da cidade. Trata-se de identificar em que medida a população-alvo foi beneficiada pelo programa, cuja iniciativa pertence a duas organizações não governamentais atuantes no local, uma nacional e a outra internacional. Utilizou-se a pesquisa qualitativa, com técnicas de pesquisa bibliográfica $e$ documental, além da aplicação de entrevistas às famílias participantes do programa. Os resultados da pesquisa, mostram que o programa trouxe melhorias, tais como a facilidade e garantia no acesso à água, porém suscita questões muito mais profundas e complexas relacionadas à aspectos financeiros, de gênero, políticos $e$ de desenvolvimento local.
\end{abstract}

Palavras-chave: Terceiro setor. Organizações não governamentais. Programa de Cisternas.

\begin{abstract}
This study aims to analyze the Cisterns Program, implemented in the rural region of the Barreira city (CE). The access to water is a topic frequently discussed in the community. In the region, water supply problems are diverse, especially for communities located far away from downtown. It intends to identify the extent to which the target population was benefited by the program, whose initiative belongs to two nongovernmental organizations operating on the location, a national and an international ones. It was conducted a qualitative research, with bibliographic and documentary research techniques, in addition to the application of interviews to families attending the program. The survey results show that the program has brought improvements, such as ease and guarantee access to water supply, but it raises much deeper and more complex issues related to financial, gender, political and local development aspects.
\end{abstract}

Keywords: Third sector. Non-governmental organizations. Cisterns Program

\footnotetext{
${ }^{1}$ Graduada em Administração Pública pela Universidade da Integração Internacional da Lusofonia Afro-Brasileira. Email: victoria.xavier.397@gmail.com

2 Doutora em Ecologia Aplicada da Escola Superior de Agricultura Luiz de Queiroz da Universidade de São Paulo ESALQ/USP, professora adjunta do curso de Administração Pública do Instituto de Ciências Sociais Aplicadas da Universidade da Integração Internacional da Lusofonia Afro-Brasileira (ICSA/UNILAB). E-mail: akanikadan@unilab.edu.br
} 


\section{Introdução}

Os problemas sociais, tais como desigualdade, desemprego, violência, criminalidade, saúde precária, baixo investimento em educação, ausência de habitação estiveram sempre presentes na história da vida em sociedade. A região Nordeste, com uma área de 1.554.291,744 km², questões relacionadas à seca e a escassez de água são recorrentes. São $982.566 \mathrm{~km}^{2}$ de extensão do Semiárido brasileiro, cerca de $18 \%$ do território nacional. No Ceará, é onde está concentrada a maior parte deste semiárido; segundo a Articulação no Semiárido Brasileiro (ASA Brasil), são 175 municípios cearenses que fazem parte deste espaço (ASA, 2019).

A ASA Brasil caracteriza o semiárido como região com baixo volume de chuvas, com alta variabilidade espacial e temporal responsável pelas secas e a baixa absorção de água no solo. Em todo o Nordeste, é sabido dos problemas relacionados à água, seja por fatores estruturais, como problemas nas gestões locais e ausência de políticas públicas; seja por fatores naturais, como o clima e temperatura, escassez de água nos rios e de chuvas, que atingem diretamente as casas de muitas famílias no interior do Ceará. No município de Barreira (CE), que faz parte do semiárido brasileiro, essa situação não é diferente, os problemas de falta de água são frequentes.

No entanto, as ações e políticas sociais que buscam lidar com essas questões ainda não são suficientes. As discussões sobre o semiárido brasileiro são crescentes; nota-se um cenário de preocupação com o bem-estar das famílias que vivem nessa realidade. Com isso duas organizações não governamentais engajaram-se nessa causa. A Associação Internacional ${ }^{3}$ criou o Programa de Cisternas em cooperação com a Organização $\mathrm{Nacional}^{4}$. O programa tem como objetivo auxiliar pela construção de cisternas, a captação de água para famílias que estão localizadas nas áreas mais afastadas do acesso a água no estado do Ceará. Com isso, o presente trabalho busca responder a seguinte questão: Em quais aspectos da vida dessas famílias foi percebida uma maior melhoria após o programa?

Este trabalho justifica-se pela necessidade de se compreender o papel das organizações não governamentais na execução de projetos sociais. Deseja-se conhecer a sua efetividade na utilização dos recursos, na perspectiva dos beneficiários dos projetos e sua contribuição para a gestão pública.

A partir das questões levantadas, o objetivo geral deste estudo é: analisar o Programa de Cisternas desenvolvido pela Associação Internacional em cooperação com a organização Nacional e

\footnotetext{
${ }^{3}$ Optou-se por omitir o nome das organizações não-governamentais

${ }^{4}$ Idem
} 
observar os aspectos que melhoraram as vidas das famílias beneficiadas do município de Barreira no Estado do Ceará.

\section{Terceiro Setor e as Organizações Não Governamentais (ONGs)}

O termo terceiro setor é apresentado como uma justificativa ideológica do desengajamento das ações do Estado (FRANÇA FILHO, 2002). Por isso, na década de 90 é que o terceiro setor teve grande consolidação, com a criação da Lei do Terceiro Setor, a qualificação de Organizações da Sociedade Civil de Interesse Público, as OSCIPs, o que permitiu parcerias com órgãos públicos e privados (OLIVEIRA \& GODÓI-DE-SOUSA, 2015).

No Brasil, o terceiro setor tem início com movimentos religiosos da época, mais especificamente com a criação da Santa Casa de Misericórdia de Santos, em 1943, que tinha apoio da Igreja Católica. Com o regime militar e devido às várias mudanças que ocorreram nessa época, os movimentos sociais ganharam força diante da crescente onda de insatisfação da população referente à política (DE ALBUQUERQUE, 2006).

O Terceiro Setor corresponde a fundações, associações, organizações não governamentais, entidades filantrópicas, ou seja, instituições de iniciativa privada sem fins lucrativos (FERNANDES, 1994). Segundo Salomon e Anheier (1992, apud, FRANÇA FILHO, 2002, p. 10.) e segundo a pesquisa intitulada As Fundações Privadas e Associações sem fins Lucrativos no Brasil - FASFIL, são utilizados os critérios elaborados pela ONU junto a Universidade John Hopkins (IBGE, 2019) para caracterizar as organizações do terceiro setor, ou seja, devem apresentar cinco características essenciais, sendo elas: 1) formais ou legalmente constituídas; 2) privadas, que não integram o aparelho do Estado; 3) independentes, tendo capacidade de administrar suas próprias ações e atividades; 4) sem fins lucrativos, que não terão como principal finalidade a geração de lucros, podendo ainda tê-los e não serão distribuídos para os seus integrantes; 5) apresentar certo nível de participação voluntária. França Filho (2002) complementa e diz que estas organizações não devem fazer parte de partidos políticos e nem ser de gênero religioso.

Por muito tempo as organizações do terceiro setor enfrentaram dificuldades com relação a sua regulamentação, uma vez que não existiam normas que as regulassem, além de dificuldades relacionadas à captação de recursos, principalmente as pequenas instituições. Esses fatores trouxeram como consequência a ausência de controle de recursos, da prestação de contas e de verificadores da atividade prestada. Foi criada a Lei 13.019/2014, sancionada em 31 de julho de 2014, estabelecendo 
o Marco Regulatório das Organizações da Sociedade Civil (MROSC), que regulamentou as parcerias entre a Administração Pública e as Organizações da Sociedade Civil. A lei define, além de outros pontos, diretrizes para o fomento da colaboração dos governos com organizações da sociedade civil.

As Organizações da Sociedade Civil (OSC) refere-se a um termo empregado recentemente pela Lei do Terceiro Setor, considerando qualquer entidade privada sem fins lucrativos com objetivo social, as sociedades cooperativas e as organizações religiosas. Nesse conceito, encontram-se as Organizações não Governamentais (ONGs), entidades criadas para atender as necessidades da população compostas pela própria sociedade.

As Organizações não governamentais foram utilizadas popularmente para se referir a qualquer organização social, porém juridicamente, as organizações não governamentais são correspondentes às fundações e associações. Por muito tempo, utilizou-se o termo para designar organizações dos movimentos populares, organizações filantrópicas e de caridade, assim Organizações Sociais, Associações e ONGs eram tidas como sinônimo. "Quando falamos de Organizações Não Governamentais - ou ONGs - no seu sentido mais estrito, falamos de organizações ligadas ao desenvolvimento e à defesa de direitos, ou seja, de uma parte da sociedade civil no seu sentido mais politizado" (MENDONÇA, 2013, p.8).

No Brasil, as ONGs aparecem com maior significado no período da ditadura militar através da resistência da população em lutar pelos seus direitos e necessidades. Mas o termo ONG foi entendido e começou a ser consolidado na conferência mundial da Organização das Nações Unidas - ONU, no Rio de Janeiro, Brasil, na Eco-92, como sinônimo de entidades sem fins lucrativos (OLIVEIRA \& HADDAD, 2001).

As ONGs são entidades do terceiro setor, de caráter privado, que tem como função desenvolver trabalhos e atividades sem a finalidade de obter lucro. As ONGs tem atuação diversificada, podendo exercer trabalhos nas áreas sociais, de saúde, ambientais, entre vários outros. Assim como foi falado sobre o terceiro setor, as ONGs surgiram como parte dele, com o objetivo de suprir a ausência do Estado com relação a sua atuação em benefício da sociedade.

Para a Associação Brasileira de Organizações não governamentais (ABONG), segundo o que está disposto em seu estatuto no art. $2^{\circ}$, são consideradas Organizações Não Governamentais, as entidades juridicamente constituídas sob a forma de fundação ou associação, sem fins lucrativos, autônomas e pluralistas. Elas devem ter o compromisso com a construção de uma sociedade democrática, participativa e com o fortalecimento dos movimentos sociais de caráter democrático, atestadas pelas suas trajetórias institucionais e pelos termos dos seus estatutos (ABONG, 2016). 
Trabalham em defesa de uma causa social e/ou política. As ONGs surgiram principalmente em locais e regiões que buscavam a solução para grandes problemas. Muitas delas atuam em comunidades distantes com pouco ou nenhum acesso às políticas governamentais.

O Marco Regulatório das Organizações da Sociedade Civil - MROSC trouxe a normatização para estas organizações, e aquelas notícias sobre ONGs corruptas que praticaram violações diminuíram, uma vez que o controle sobre essas organizações é maior.

\section{Financiamento das Organizações da Sociedade Civil: a Cooperação Internacional}

As principais fontes de financiamento das organizações da sociedade civil são: Recursos Públicos, Cooperação Internacional para o Desenvolvimento, Novos Formatos de Mobilização de Recursos e Investimento Social Privado (ISP) (MENDONÇA et al, 2013).

O Instituto de Pesquisa Econômica Aplicada - IPEA (LOPEZ \& ABREU, 2014) publicou uma pesquisa acerca do que mobilizou o Estado a cooperar com ONGs na implementação de políticas públicas. Com a pesquisa, foi possível considerar que a parceria entre Estado e ONGs está imputada em suas capacidades no que diz respeito à expertise, a capilaridade, a flexibilidade e ao engajamento nas políticas propostas. Ou seja, as ONGs trabalham com mais proximidade dos beneficiários, isso faz com que entendam e definam melhor as necessidades deles.

Por outro lado, a burocracia é importante na implementação de políticas, considerando sua infraestrutura e segurança. Com isso, o estudo reforça o papel que as ONGs tem em fortalecer as políticas executadas pelo Estado.

Dagnino (2004) critica esta relação entre a sociedade civil e o Estado, caracterizando este vínculo como o dilema da confluência perversa. Trata-se de um dilema, pois a autora destaca dois projetos vigentes que necessitam de uma sociedade civil atuante, há o processo de construção democrática em ambos os projetos. De um lado encontra-se o projeto neoliberal com o encolhimento das responsabilidades sociais do Estado e sua transferência para a sociedade civil. De outro lado, há um projeto democratizante, participativo, que emergiu da ditadura militar e dos diferentes esforços nacionais de aprofundamento democrático (Constituição de 1988), com a criação de espaços públicos: conselhos gestores, orçamento participativo. A autora questiona essa larga presença das ONGs como o avanço deste modelo neoliberal, chamando a atenção para um maior aprofundamento dos papeis que desempenham as diferentes organizações, para que se possa diferenciar os projetos políticos que 
respondam aos direitos universais ou que respondam às ações de indivíduos que desejam ser solidários com os mais pobres, numa perspectiva de caridade.

O questionamento reside na redefinição da noção de sociedade civil que sofreu uma aproximação perigosa do termo ONG. Segundo a autora, cada vez mais, as ONGs abandonam seu vínculo com os movimentos sociais, pois tem as agências internacionais e o Estado como financiadores, se tornaram prestadoras de serviços e não mais representam a sociedade civil.

Em grande parte dos espaços abertos à participação de setores da sociedade civil na discussão e na formulação das políticas públicas com respeito a essas questões, estes se defrontam com situações nas quais o que se espera deles é muito mais assumir funções e responsabilidades restritas à implementação e a execução de políticas públicas, provendo serviços antes considerados como deveres do Estado, do que compartilhar o poder de decisão quanto à formulação dessas políticas (DAGNINO, 2004, p. 152).

Esta parceria do Estado com a sociedade civil organizada é uma das fontes de financiamento das ONGs. Muitas delas, dependem em grande parte de recursos públicos. Uma outra forma de captação de recursos, denominada por Mendonça et al (2013) como Novos Formatos de Mobilização de Recursos, referem-se às doações de indivíduos, criação de fundos comunitários, ferramentas que se utilizam da web, das redes sociais e o telemarketing. Há ainda o Investimento Social Privado (ISP) caracterizado como o investimento que é feito por grandes empresas. São cerca de $94 \%$ das organizações privadas com mais de 500 funcionários responsáveis pela doação de recursos para questões sociais (MENDONÇA et al, 2013).

Com o fortalecimento da democracia e da justiça social foi possível a abertura para mais uma forma de financiamento das organizações da sociedade civil, a cooperação internacional, foco deste estudo. A cooperação internacional cresce a cada dia, inclusive para além da figura do Estado-Nação, tendo em vista a importância de organizações não governamentais. A cooperação internacional pode ter por objeto algum bem jurídico ou atividade ligada aos mais diversos ramos jurídicos: penal, administrativo, processual, trabalhista, tributário, previdenciário, dentre tantos outros (VALE, 2014).

A cooperação internacional atua na luta pelos direitos sociais principalmente no cenário de países em desenvolvimento. Buscando gerar mais desenvolvimento de maneira justa, através do envio de recursos financeiros para projetos e programas sociais. Essas instituições podem ser organizações públicas ou privadas.

É importante ressaltar que essas relações entre Estado ou organizações internacionais são de fato complexas em diferentes níveis, mas é fundamental estabelecermos que as ONGs ou OSCs não 
substituem o trabalho realizado pelo Estado, tampouco acredita-se que tenham essa intenção, pois o que muitas vezes ocorre é que ao prestarem serviços públicos e atividades assistencialistas, essas organizações também fazem o papel de cobrar políticas públicas para uma melhor atuação desses projetos, geralmente em âmbito nacional, podendo também ampliar projetos já implementados. Segundo França Filho (2002) ao referenciar Laville, o autor traz uma questão importante, a ligação do terceiro setor com o Estado, dizendo por sua vez, que essa relação de trabalho e contribuição pode fazer com que novas iniciativas e ações públicas sejam geradas. O autor cita como exemplo as sociedades de socorro mútuo na Europa, que trouxeram a ideia da previdência estatal, passando a ser utilizada pelo Estado.

Acredita-se que as relações de parceria entre o Estado e/ou com organizações internacionais são importantes e necessárias, pois a comunidade absorverá muito mais benefícios desta forma, sobretudo se a parceria for justa entre essas organizações e o Estado, e analisando-se sempre criticamente esta relação.

No caso do município de Barreira (CE), políticas públicas voltadas para o semiárido e sua convivência são fundamentais, a evolução dessas políticas e tecnologias trazem muitos benefícios e pontos positivos na convivência com o semiárido e com os problemas relacionados a seca e a falta de água no geral.

Assim, é fundamental ressaltar que o Programa de Cisternas não tem financiamento público, está pautado na cooperação internacional, que atualmente pode ser a melhor alternativa para essas políticas e programas sociais, uma vez que o cenário político atual é preocupante, devido aos governos se ausentarem de suas atribuições.

\section{Metodologia}

Foi utilizado o método de pesquisa exploratória, que tem como objetivo "proporcionar maior familiaridade com o problema, com vistas a torná-lo mais explícito ou a constituir hipóteses” (GIL, 2002, p.41). O estudo baseou-se no Programa de Cisternas desenvolvido pela Associação Internacional em cooperação com a Organização Nacional, quanto à melhora nas vidas das famílias beneficiadas. Para isso a abordagem de pesquisa é classificada como qualitativa, "se preocupa com aspectos da realidade que não podem ser quantificados, centrando-se na compreensão e explicação da dinâmica das relações sociais." (FONSECA, 2002, p.20), uma vez que serão tratados aqui de aspectos subjetivos, que não podem ser expressos numericamente. 
A pesquisa utilizou-se da revisão bibliográfica e documental, com o foco nos temas de "terceiro setor", "organizações não governamentais" e "cooperação internacional”. A pesquisa bibliográfica utiliza-se de registros já disponíveis resultantes de pesquisas anteriores, como livros e artigos. A pesquisa documental se relaciona a coletas de dados, tais como jornais, fotos, filmes, gravações e documentos legais (SEVERINO, 2007, p.122-123) feitas no âmbito da Organização Nacional que foi realizado antes da ida a campo com a finalidade de conhecer e selecionar as famílias.

A análise dos dados foi feita considerando-se o que Cohen e Franco (1993) sugerem para uma análise de projetos sociais quanto à eficiência em sua utilização e a comprovação de sua eficácia para alcançar seus objetivos. Assim, nesta análise, os critérios básicos utilizados são a eficiência e a equidade, que estão relacionadas à satisfação das necessidades básicas dos indivíduos. "A política social cumpre o objetivo de investir em recursos humanos (que pode ser interpretado como "ensinar a pescar") mas necessita que o sistema esteja em condições de demandar esse pessoal" (COHEN \& FRANCO, 1993, p.22).

A Organização Nacional se dispôs a fornecer os dados necessários possíveis para a pesquisa e uma funcionária ficou encarregada de ajudar com as fichas dos beneficiários e a localizá-los no município, visto o seu conhecimento de campo. Esta organização, segundo o que está descrito em seu site (ORGANIZAÇÃO, 2019), foi fundada em 2001 no município de Barreira (CE) a partir das necessidades de promover ações e criar projetos que auxiliassem na promoção do direito a água. Tais ações se circunscreveram ao município de Barreira, mais especificamente àqueles distritos localizados a muitos quilômetros de distância do centro da cidade e seriam equivalentes às políticas públicas de nível municipal (SILVEIRA \& SOUZA, 2016).

Para a pesquisa de campo, durante as visitas feitas a Organização Nacional, as fichas dos beneficiários foram analisadas e com isso foram selecionadas cinco famílias beneficiadas entre os anos de dois mil e dezessete (2017) e dois mil e dezenove (2019) nas comunidades de Jatobá II e Olaria II.

Ambas as comunidades de Jatobá II e Olaria II estão localizadas nas margens periféricas do centro do município de Barreira (CE), situadas em pontos diferentes da cidade, no início da zona rural do município. Socioeconomicamente parecidas, em sua maioria são famílias de baixa renda, geralmente composta por agricultores e agricultoras rurais e pequenos produtores de castanha de caju.

O uso de entrevistas foi utilizado como técnica de pesquisa, a partir de visitas às casas, com um roteiro de doze perguntas semiestruturadas. As entrevistas foram feitas de modo presencial nos dias 17 e 20 de dezembro de 2019. Foram realizadas cinco entrevistas, onde uma pessoa por família 
respondeu perguntas referentes ao programa. Cada entrevista foi feita na casa do respectivo entrevistado, assim os indivíduos poderiam ficar mais à vontade para conversar. Todos os entrevistados assinaram uma autorização onde permitiram o uso dos dados para o presente artigo.

Com relação à Associação Internacional, foi estabelecido contato com o coordenador da instituição, uma vez que esta é a criadora e financiadora do programa. Foi utilizado uma espécie de questionário com 10 perguntas relacionadas a instituição e seu trabalho, este foi encaminhado por $e$ mail e o coordenador do programa respondeu às perguntas. A Associação Internacional também foi bastante prestativa às indagações, levando-se em consideração que sua sede é na Itália.

A Associação Internacional, segundo seu site oficial, é uma entidade sem fins lucrativos fundada em 1998, em Bérgamo, Itália. A associação foi criada por um grupo de amigos cuja primeira iniciativa foi a de ajudar um centro de apoio para crianças portadoras de HIV/AIDS em Salvador (BA). A entidade também ajudou outras associações que trabalham no campo da saúde, educação e construção civil e em outras áreas do mundo como o México, Nicarágua, Turquia, Moçambique, Bósnia e Afeganistão. Atualmente, a associação realiza projetos em todo o estado do Ceará e na Itália.

Com isso, o presente trabalho está pautado em informações obtidas e utilizadas de maneira responsável, levando-se em consideração o respeito à privacidade de todos os indivíduos envolvidos.

\section{O Programa de Cisternas em Barreira (CE)}

O município de Barreira (CE) localiza-se na região do Maciço de Baturité, distante cerca de 72 quilômetros da capital Fortaleza. Sua população estimada em 2018 foi de 21.104 habitantes (IPECE, 2018).

O programa de cisternas foi iniciado no ano de 1999, quando o representante da Associação Internacional junto ao fundador da Organização Nacional conheceram o Pároco da Igreja Matriz de Barreira no Fórum de Semiárido em Fortaleza (CE). Este pediu ajuda às organizações sobre a falta de água na cidade, mas foi um Padre italiano da Pastoral da Terra que deu a ideia das cisternas.

Com isso foi criado o Programa de Cisternas, visando melhorar a qualidade de vida das famílias que

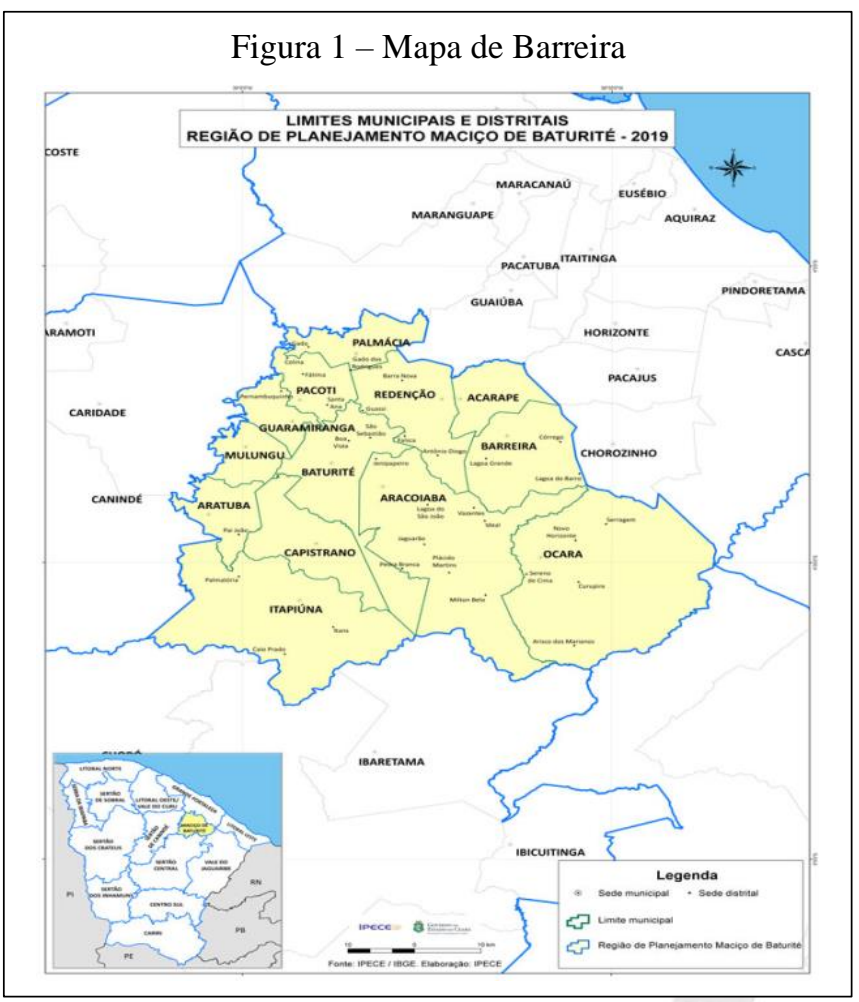


vivem nas áreas mais afastadas do acesso a água no semiárido cearense por meio da construção de cisternas de concreto para o armazenamento de água.

Cabe destacar que o programa de cisternas desenvolvido pela Associação Internacional não é o mesmo programa de cisternas do Governo Federal. Apesar de partirem da mesma problemática, que é a falta d'água, os programas diferem quanto à fonte de recursos financeiros e a utilização dessas águas captadas.

O programa de cisternas do Governo Federal (BRASIL, 2020) tem foco não apenas em famílias que são atingidas pela seca ou que lhes falte água frequentemente. A implementação ocorre também nas escolas e nas atividades produtivas, com capacidade de até 52 mil litros de água. As famílias devem estar registradas no Cadastro Único para Programas Sociais do Governo Federal, este atua principalmente na região semiárida brasileira. O financiador dos recursos é o próprio governo federal que necessita da parceria de organizações da sociedade civil para a construção dessas cisternas. Logo no início do programa, o material utilizado para a construção das cisternas era de plástico, o que gerou muita insatisfação por parte da ASA e de agricultores que relataram os problemas relacionados à durabilidade, deformação e custo. Então, a partir de 2014 passaram a utilizar as cisternas de placa (COSTA, 2014).

O programa de cisternas da Associação Internacional é financiado pela própria entidade por meio da captação de recursos que realiza. Para obter o benefício, as famílias precisam estar afastadas de fontes de acesso à água, sendo o uso basicamente doméstico. Assim como o governo federal, esta associação depende de outra organização da sociedade civil para construir a cisterna, neste caso, a Organização Nacional.

\section{Resultados e Discussões}

Os dados obtidos mostram que até o dia 31 de dezembro de 2019, foram construídas 442 (quatrocentos e quarenta e duas) cisternas, sendo 2.617 pessoas beneficiadas. Conforme o que está disponibilizado no site da Associação Internacional (Internacional, 2020) e como foi disponibilizado pela Organização Nacional, o programa possui duas diretrizes: 1) Construção de cisternas de concreto para a captação de água da chuva: cada família recebe uma cisterna, com capacidade que varia de 10.000 até 16.000 litros. 
Figura 2 - Cisterna construída no quintal de uma das famílias entrevistadas

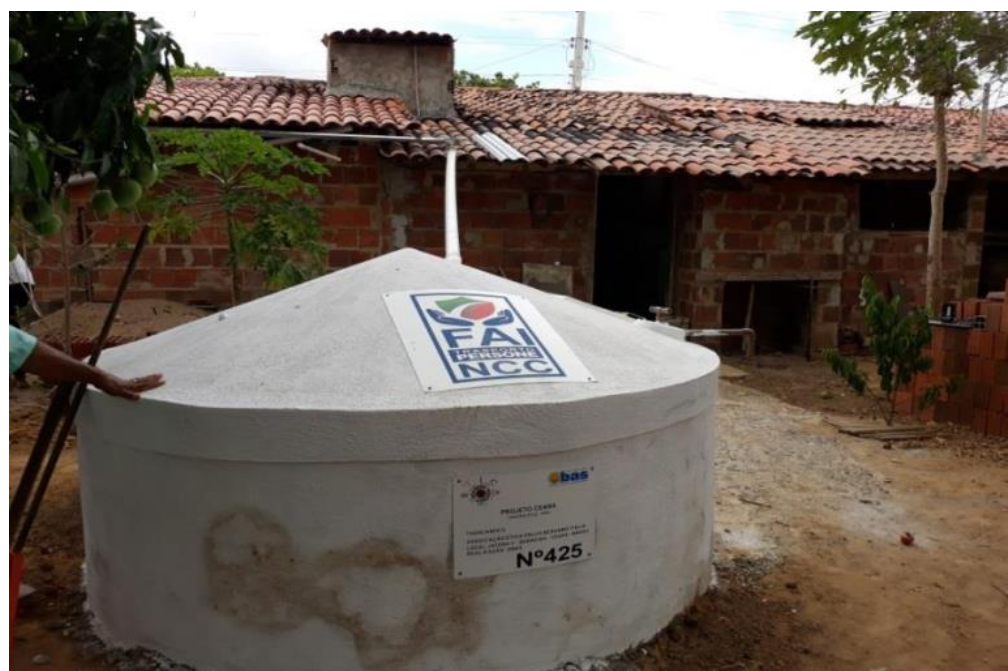

Fonte: autoras (2019)

A seleção desta família é feita com base em três critérios, sendo eles: a) família mais numerosa; b) família que vive mais longe das fontes de água (rios, lagos, represas e poços públicos); e, c) menores de idade devem estar na escola. A outra diretriz: 2) Formação profissional para jovens agricultores especializados em técnicas de convivência com o semiárido nordestino.

Para receber a cisterna de 16.000 litros, a família deve ser composta por no mínimo cinco pessoas. Para a de 10.000 litros, deve ser composta por no mínimo quatro pessoas. Em ambas as famílias devem-se ter filhos. As famílias selecionadas comprometem-se a participar de um curso de manutenção da cisterna, disponibilizado pela Organização Nacional, além de ajudar no trabalho de escavação para construção da cisterna (Organização, 2019).

Uma das dificuldades para manter os projetos sociais reside na captação de recursos. As organizações financiadoras desempenham este papel de suprir cenários de dificuldades, como relatado pela Associação Internacional. A forma como se mantém depende da doação de pessoas físicas e pessoas jurídicas que se interessam pelo projeto de construção de cisternas. Seu representante relembrou a chegada da organização no Brasil, nos anos 1990, no governo de Fernando Henrique Cardoso, quando encontraram um cenário de escassez em relação às ações voltadas às populações mais necessitadas e que atualmente vê um retrocesso no país com relação à utilização de seus recursos.

Na visita de campo, pôde-se perceber primeiramente, que as casas, das famílias beneficiadas, estão localizadas a uma distância considerável do centro do município. As famílias entrevistadas estavam em duas localidades do município de Barreira, Jatobá II e Olaria II, onde o acesso à água é 
mais difícil quando comparado ao acesso na área urbana e central do município. Outra observação é que as casas visitadas aparentam ser mais simples, de alvenaria e com construções mais antigas.

Com relação às entrevistas, foi clara a importância e os benefícios trazidos pelo programa, pois todos os entrevistados se mostraram felizes e agradecidos por terem sido beneficiados. Tudo isso resulta em uma aproximação maior dessas entidades com as comunidades e os beneficiários, conforme foi observado na pesquisa do IPEA de Lopez e Abreu (2014).

Quando perguntados sobre como e onde buscavam água antes da instalação das cisternas, os entrevistados lembraram-se de como era difícil, pois tinham que obtê-la em algum lugar geralmente distante de casa ou comprar carro pipa. Os entrevistados relataram ser muito cansativa essa busca por água. Com a cisterna, a preocupação com este fator diminuiu consideravelmente, tornando a vida mais confortável. "Era horrível, a gente tinha que ir buscar lá no chafariz, lá longe, a gente ia buscar de tambor em tambor. Todo dia tinha que ir buscar...” (ENTREVISTADO 1). "Às vezes quando faltava, eu contratava carroça pra vir deixar um tambor de água, porque falta muita água em Barreira...agora, se passar um mês sem água da CAGECE - Companhia de Água e Esgoto do Ceará, dá para aguentar" (ENTREVISTADO 2).

Outros benefícios trazidos pela cisterna são destacados a partir de algumas afirmações feitas pelos beneficiados, a saber: a) A economia financeira com água: tanto no que diz respeito à conta de água encanada, que passa a ser menos utilizada, como à compra de água para beber e para ser utilizada nos serviços da casa; b) a inexistência de preocupação com a falta de água encanada e consequentemente a diminuição do trabalho para buscar em poços e cacimbas ${ }^{5}$ distantes.

Sobre a utilização da água, das cinco famílias entrevistadas, duas afirmaram utilizar a água, quando captada da chuva, somente para beber. Já as demais além de utilizar para beber, utilizam nos serviços da casa, para cozinhar, lavar roupas, tomar banho, lavar louças, além de cuidar das pequenas plantações que alguns possuem em seus quintais. Assim, segundo os entrevistados, o programa impacta de maneira positiva em suas vidas cotidianas, uma vez que cumpriu o seu papel, que é o de facilitar a vida com relação à água nessas famílias.

Sobre o armazenamento da água, as famílias participaram de cursos e palestras na sede da Organização Nacional, onde aprenderam a cuidar da cisterna e a mantê-la em funcionamento. Todos aparentaram entender bastante sobre aspectos relacionados a como tratar a cisterna, pois em algum

\footnotetext{
${ }^{5}$ Cacimbas ou olhos d'água são escavações rasas feitas em riachos temporários para se aproveitar as águas subterrâneas, resultantes da infiltração da água das chuvas no solo. (PORTO et all, 2004)
} 
momento já possuíram algum tipo de "cacimba" em casa, visto que isso parece ser um costume comum dos mais antigos que vivem no Ceará.

Um aspecto importante que foi possível perceber nas entrevistas, foi com relação a quantidade de água armazenada. A cisterna de 16.000 litros é disponibilizada somente às famílias que possuem no mínimo cinco pessoas na casa e a de 10.000 litros no mínimo quatro pessoas, mas todas as famílias relataram fazer uso conjunto da cisterna com a água encanada, quando não está em falta; ou seja, nenhuma das famílias utiliza apenas a água da cisterna. Este resultado mostra a necessidade de um maior aprofundamento desses relatos, pois em outro estudo com outras comunidades, a água armazenada não é suficiente (COSTA, 2014).

Outra questão analisada, é sobre as mulheres e sua maior preocupação em falar sobre o que mudou em suas vidas cotidianas. Das cinco famílias entrevistadas, quatro tinham representantes mulheres e todas buscaram junto à Organização Nacional, o benefício da cisterna, visto a grande necessidade que tinham e as grandes dificuldades acerca da água. Ressalta-se que estas mulheres buscavam há anos solucionar esta questão. O que foi notadamente percebido, é que as mulheres, por terem mais trabalho e por fazerem mais serviços em casa, de certa forma valorizam os benefícios que tal programa trouxe.

Pontes (2013) retrata o papel da mulher sertaneja e da sua relação com a água. Ela tem um papel muito importante nessa relação, uma vez que além de cuidar dos serviços da casa, cuida das atividades agrícolas e em sua maioria é ela que cuida do abastecimento de água. Apesar da subestimação da mulher, esta assume o papel de chefe de família quando os homens precisam se ausentar. O autor utiliza o caso do projeto "Um Milhão de Cisternas Rurais (P1MC)", que tem como um de seus critérios, casas de famílias beneficiadas com mulheres como chefes de família, o que traz uma forma de valorização do papel da mulher.

O papel das mulheres no semiárido é um retrato de como são fortes e poderosas, mesmo nem todas tendo consciência disso. São elas que sustentam a unidade familiar, jovens ou idosas, trabalhadoras domésticas ou intensamente no campo e continuam resistindo e lutando pela sobrevivência, encontrando formas dentro da lógica da convivência. Por isso, o fim das longas caminhadas, com peso das latas d'água na cabeça, propiciado pelas cisternas, é um começo para uma boa convivência no semiárido (PONTES, 2013, p. 19).

Com isso, é importante ressaltar o papel da mulher, além de estimular o desenvolvimento de ações e políticas que incluam as questões de gênero e das mulheres que vivem no semiárido e nas áreas rurais. 
Os entrevistados também mostraram sua indignação por parte do sistema hídrico do município, onde relataram a falta de água por até dois meses seguidos. Isso mostra que no município de Barreira (CE), os problemas de falta de água vão muito além do clima e da região em que estão inseridos. Há problemas estruturais e governamentais, tais como encanamento antigo, o que impede que a água chegue às casas por uma semana inteira sem interrupções. Além do desinteresse da gestão local em lidar com essa questão. "Estava faltando água? Chegou, só deu pra abastecer a cisterna... se não fosse a cisterna..." (ENTREVISTADO 4)

Outra situação também destacada por Dagnino (2004) é com relação ao papel das organizações da sociedade civil em se tornarem apenas prestadoras de serviços públicos, e deixar de lado o seu papel de representantes da sociedade em relação a suas reais necessidades. No presente estudo, nota-se um esforço em permitir a convivência com o semiárido e a luta pelo direito a água. Para o futuro, há que se ter o cuidado de não transformar suas ações em um programa de caridade. A publicidade dada às ações realizadas pelo programa poderá trazer visibilidade e novos projetos sociais e a criação de políticas públicas.

\section{Considerações Finais}

$\mathrm{Na}$ reta final deste estudo, considera-se que foram apresentados os aspectos relativos ao tema proposto. A pesquisa pôde levantar questões e reflexões que ficaram em aberto, mas que podem e devem ser preenchidas posteriormente. Com isso, os objetivos aqui propostos, assim como a questão principal que o norteou, sobre os benefícios que o Programa de Cisternas trouxe, foram alcançados. O acesso à água é uma realidade nas atividades domésticas das famílias consideradas.

O Programa de Cisternas nasce da necessidade da população de Barreira (CE) em armazenar água, visto os problemas acerca do abastecimento já conhecidos no município. O programa visa atender as populações rurais e mais afastadas do centro, que se viam excluídas desse acesso. Os dados mostram que o Programa de Cisternas foi bem recebido pelos seus beneficiários, todos se mostraram satisfeitos e os resultados foram positivos em suas vidas, pois agora contam com a facilidade e garantia no acesso à água.

Ainda se destaca como lacuna do programa, a falta de propostas acerca do principal problema que se tem no município sobre o acesso à água, onde o abastecimento é falho devido às razões que não ficaram explícitas no estudo. Há deteriorações no encanamento, há períodos de estiagem na região, ou seja, esses questionamentos poderiam ser utilizados de forma a atingir a raiz do problema, 
a partir de uma discussão e de um levantamento com a própria comunidade sobre esses fatos. Com uma sociedade civil propositiva e um projeto bem planejado seria possível apresentar um modelo mais efetivo de combate à falta de água.

As organizações do terceiro setor, por sua vez, enfrentam grandes dificuldades em sua trajetória, reconhecimento, sustentabilidade financeira e concorrência para se consolidarem no país. Sua luta para a defesa dos direitos sociais da população, esbarra na principal dificuldade para a sua existência, que é a captação de recursos.

As parcerias com o Estado, as cooperações internacionais e tantas novas formas de captação de recursos são de grande importância para o crescimento, consolidação e manutenção de projetos e políticas sociais no Brasil.

No entanto, a questão que fica nesta pesquisa é acerca da permanência do programa e da preocupação em relação a sua continuidade. Os problemas referentes ao abastecimento de água no município parecem não cessar, com isso, o programa apenas reforça a sua importância. Reforça igualmente a necessidade de compreender o papel das ONGs no processo de desenvolvimento local pois neste caso as entidades envolvidas mostraram-se muito responsáveis na maneira como tratam a vida e as necessidades dessas famílias, são visíveis os impactos deixados. Ressalta-se o descaso por parte de autoridades governamentais locais o fato de o município ser conhecido pela população e por seus gestores, por seus problemas acerca do abastecimento de água, e possuir apenas um programa que busque tratar dessas questões.

Portanto, fica evidente a necessidade de investimentos e de novas políticas que de alguma forma venham a suprir as necessidades da população residente em Barreira (CE) que sofre diariamente com os problemas de acesso a água.

Enfim, pode-se verificar que o acesso à água traz questões muito mais profundas acerca de questões sociais e de vulnerabilidade que atinge toda a população, em diferentes níveis. Discutir a água se mostrou muito mais complexo, levantando-se questões relacionadas à aspectos financeiros (origem dos recursos e gestão do projeto), de gênero, políticos, de desenvolvimento local (atuação das ONGs e governo), de participação social e de saúde dada a pandemia de Covid-19 e sua influência no agravamento de toda essa situação, que poderiam ser temas para estudos futuros.

\section{Referências}

ABONG - Associação Brasileira de Organizações Não Governamentais. Estatuto Social. Abong. São Paulo, 16 de março de 2016. 
ASA - Articulação do Semi-árido Brasil. Disponível em: http://www.asabrasil.org.br. Acesso em 15 jul 2019.

BRASIL. Lei ${ }^{\circ}$ 10.406, de 10 de janeiro de 2002. Institui o Código Civil. Diário Oficial da União: seção 1, Brasília, DF, ano 139, n. 8, p. 1-74, 11 jan. 2002. Disponível em: http://www.planalto.gov.br/ccivil_03/leis/2002/110406.htm. Acesso em: 04 nov 2019.

BRASIL. Lei no 13.019, de 31 de julho de 2014. Disponível em: http://www.planalto.gov.br/ccivil_03/_ato2011-2014/2014/lei/113019.htm. Acesso em: 04 nov 2019.

BRASIL. Ministério da Cidadania. Secretaria Especial do Desenvolvimento Social. Programa Cisternas. Brasília, DF, [s.d]. Disponível em: http://mds.gov.br/assuntos/seguranca-alimentar/acessoa-agua-1/programa-cisternas. Acesso em: 21 jan 2020.

COHEN, E; FRANCO, R. Avaliação de projetos sociais. Petrópolis, RJ: Vozes, 1993.

COSTA, C.V. Análise da gestão das águas nas cisternas de placas das comunidades: Santa Vitória e Patos no Município de Granjeiro - CE. Dissertação (mestrado profissional) - Universidade Federal do Ceará, Mestrado Profissional em Gestão de Recursos Hídricos, Fortaleza, 2014.

DAGNINO, E. Construção democrática, neoliberalismo e participação: os dilemas da confluência perversa. Política \& Sociedade, v. 3, n. 5, p. 139-164, 2004.

DE ALBUQUERQUE, A.C.C. Terceiro setor: história e gestão de organizações. Summus Editorial, 2006.

Associação Internacional. Página Inicial. [s.d]. Disponível em: https://www.internacionalbrasile.it/home-3/. Acesso em: 06 jun 2019.

FERNANDES, R.C. Privado porém público: o terceiro setor na América Latina. Rio de Janeiro: Relume-Dumará, 1994.

FONSECA, J. J. S. Metodologia da pesquisa científica. Fortaleza: UEC, 2002. Apostila.

FRANÇA FILHO, G. C. de. Terceiro setor, economia social, economia solidária e economia popular: traçando fronteiras conceituais. Bahia Análise \& Dados, v.12, n. 1, p. 9-19, 2002.

FUCHS, R. M. Manual do terceiro setor. Jardim Paulista: Instituto Pro Bono, 2013.

GIL, A. C. Como elaborar projetos de pesquisa. São Paulo, v. 5, n. 61, 2002.

IBGE, Instituto Brasileiro de Geografia e Estatística. As fundações privadas e associações sem fins lucrativos no Brasil: 2016. Rio de Janeiro: IBGE, 2019.

IPECE, Instituto de Pesquisa e Estratégia Econômica do Ceará. Mapa municipal de Barreira. Ceará: IPECE, 2018. Disponível em <http://ipecedata.ipece.ce.gov.br/ipece-dataweb/module/anuario.xhtml>. Acesso em: 21 jan 2020. 
LOPEZ, F. G.; ABREU, R. A participação das ONGs nas políticas públicas: o ponto de vista de gestores federais. Texto para discussão, Instituto de Pesquisa Econômica Aplicada (IPEA), 2014.

MENDONÇA, P. M. E. et al. Pesquisa arquitetura institucional de apoio às organizações da sociedade civil no brasil. Apresentação e Resumo Executivo. Articulação D3 - Diálogos, Direitos e Democracia CEAPG - EAESP - FGV, 2013.

Organização Nacional. Página Inicial. [s.d]. Disponível em: http://organizaçãonacional.org.br/. Acesso em: 06 jun 2019.

OLIVEIRA, A. C.; HADDAD, S. As organizações da sociedade civil e as ONGs de educação. Cadernos de Pesquisa, n. 112, p. 61-83, 2001.

OLIVEIRA, E. A.; GODÓI-DE-SOUSA, E. O Terceiro Setor no Brasil: avanços, retrocessos e desafios para as Organizações Sociais. Revista Interdisciplinar de Gestão Social, v.4, n.3, 2015.

PONTES, E. T. A estreita relação entre mulher e água no semiárido: o caso do programa um milhão de Cisternas rurais. Revista Latino-americana de Geografia e Gênero, v. 4, n. 1, p. 14-21, 2013.

PORTO, E.R.; BRITO, L.T.L.; ANJOS, J.B.; SILVA, M.S.L. ABC da Agricultura Familiar. Formas de garantir água nas secas 2. Barragens, cacimbas e poços amazonas. Embrapa Semi-Árido, 2004.

SEVERINO, A. J. Metodologia do trabalho científico. Cortez editora, rev. São Paulo, 2007.

SILVEIRA A. K. T. ; SOUZA, G. H. O. Organização Barreira Amigos Solidários - Obas como meio de desenvolvimento regional. In: Anais da Semana de Iniciação Científica, Faculdade do Maciço de Baturité, 2016.

VALE, H. E. G. Princípio da cooperação internacional. Revista Jus Navigandi, Teresina, ano 19, n. 3864, 29 jan. 2014. Disponível em: https://jus.com.br/artigos/26542. Acesso em: 06 jan. 2020. 